\title{
Which Humans Behave Adaptively, And Why Does It Matter?
}

\author{
Paul W. Turke \\ Evolution and Human Behavior Program, University of Michigan, Ann \\ Arbor, Michigan
}

\begin{abstract}
There has long been debate about the relevance of evolutionary theory to the study of humans. To many of us, however, the debate has shifted from whether to proceed with an evolutionary approach to how to proceed. Increasingly, it has been argued that studies of the current reproductive function of human traits make little or no contribution to the understanding of the psyche (e.g., Symons 1989). Here, on the basis of arguments about the relationship between an adaptation and an adaptive outcome, and a review of studies that assess current adaptiveness, I argue to the contrary that knowledge of the contexts in which people do or do not behave adaptively provides important information about the nature of the mechanisms that comprise the human psyche. In particular, studies that indicate that people behave adaptively in at least some contemporary environments cast doubt on many nonevolutionary constructions of human nature, and can be used now to distinguish alternative evolutionary constructions that are at odds over many issues pentaining to the human psyche's ontogeny and evolutionary background, especially the extent to which the human psyche is general purpose.
\end{abstract}

KEY WORDS: Adaptation; Adaptiveness; Cultural evolution; Demographic transition; Evolutionary psychology; Nonadaptive evolution; Reference groups; Reproductive success

\section{INTRODUCTION}

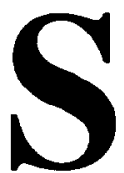

ince the dawn of the 1970's, Richard Alexander, Napoleon Chagnon, William Irons, and a handful of others have made life uncomfortable for a great many social scientists. There was a time at the University of Michigan when graduate students in cultural anthropology took pains not to be seen in the company of Alexander, lest they risk raising the ire of their faculty advisors. Thankfully, this has begun to change; a few cultural anthropologists have even become regular contributors to Michigan's Evolution and Human Behavior Program.

Received January 22, 1990; revised April 30, 1990. Address reprint requests to: Paul W. Turke, Evolution and Human Behavior Program, 100 Rackham Building, University of Michigan, Ann Arbor, MI 48109-1070. 
Has the discomfort and ire Alexander et al. have caused been the result of their advocating an invalid approach? Or is it that their approach has effectively challenged a number of cherished social science dogmas? Donald Symons and others have recently presented arguments-criticisms of the approach advocated by Alexander, Chagnon, and Irons-which, if correct, would force us to answer the first question affirmatively. I vigorously disagree with most of these criticisms, although acknowledging that there is much that is useful in the research strategies advocated by so-called evolutionary (or Darwinian) psychologists. ${ }^{1}$

The overriding theme of this paper is that knowledge of the contexts in which people do or do not behave adaptively provides important information about the nature of the mechanisms that comprise the human psyche. In turn, it is argued that recent articles deploring attempts to assess current adaptiveness are, ironically, counterproductive to the goal of illuminating mechanisms of the psyche. ${ }^{2}$ Along the way, I discuss the relationship between an adaptation and an adaptive outcome; dispute the argument that the environments to which humans are and are not adapted are captured by the Pleistocene/post-Pleistocene dichotomy; review and develop arguments suggesting that some mechanisms of the human psyche are more "general purpose" than implied in recent articles; and summarize evidence that suggests that humans in many different contemporary environments are behaving adaptively.

In many respects, the arguments in this paper parallel those of Alexander (1990), Betzig (1989), Irons (1983), Sherman (1988), and Smuts (1990). Here, however, the emphasis is on determining 1) which people behave adaptively and 2) the extent to which studies of current adaptiveness help in the derivation and testing of alternative hypotheses about the nature of the human psyche.

\section{DEFINITIONS}

Adaptation To most evolutionary biologists, an "adaptation" is an aspect of a phenotype that was designed by natural selection to serve a function (e.g., Williams 1966; Mayr 1983). As such, all adaptations, including fac-

\footnotetext{
1 As Alexander (1990) and Betzig (1989) note, an evolutionarily based focus on proximate mechanisms is well entrenched in biology (e.g., Holmes and Sherman 1982). Ironically, however, although evolutionary psychologists have recently published a large number of articles proclaiming the virtues of this approach, there are few examples of them actually practicing it. Exceptions include Thornhill and Thornhill (1983), and Cosmides (1985), Buss 1989, and Daly and Wilson (1988).

${ }^{2}$ I note that the two psychologists who have contributed most to an evolutionary psychological approach have avoided this error: "[E]vidence that human fertility has been negatively associated with material success in certain societies during certain time periods . . . should provide some valuable clues for anyone wishing to develop a Darwinian psychology of fertility decisions" (Martin Daly and Margo Wilson 1986, p. 189). I would only add: ditto for evidence of a positive association.
} 
ultative adaptations, are products of gene-environment interaction, which means that it is invalid to carve the phenotype into so-called "genetic adaptations" and "nongenetic adaptations." The tendency to think of morphological traits, such as eye color, as solely determined by genes, and learned traits, such as human foraging techniques, as solely determined by the environment indicates a poor understanding of development and the raison d'etre of phenotypes (Alexander 1979, pp. 87-98; Irons 1979a; Flinn and Alexander 1982; Turke 1984). ${ }^{3}$

The fact that adaptations are products of gene-environment interaction bears on the assertion, with which I disagree, that "Natural selection cannot select for behavior per se; it can only select for mechanisms that produce behavior' (Cosmides and Tooby 1987, p. 281; Staddon 1987, p. 180; Symons 1989). This assertion, I think, is intended to convince the reader that mechanisms comprising behaviors are adaptations, behaviors themselves are not, and therefore only the former are the proper focus of adaptationist studies. However, to the contrary, morphology, physiology, psychology, and behavior are, fundamentally, inseparable aspects of gene-environment interaction. It follows that behaviors can be adaptations every bit as much as the morphological, physiological, and psychological mechanisms comprising behaviors. 4

Thus, there are three principal components which, when linked, represent the process of adaptive evolution: there are genes-the entities which are actually accumulated by selection; there are the products of gene-environment interaction, of which some qualify as adaptations; and there is selection, which is simply differential reproductive success. Of course, random forces also play a role in evolution, but they do not produce sustained directional change, and therefore cannot principally guide adaptive evolution (e.g., Dawkins 1986).

In noting that an adaptation is the (naturally selected) continuum of development that results from gene-environment interaction, one brings attention to the fact that the function of any adaptation can be confoundedat any point in the continuum of proximate-to-ultimate function-by a significant change in the environment. Thus, just as reproductive outcomes can be confounded by environmental novelty (as is emphasized by those who criticize the study of reproductive outcomes [e.g., Cosmides and Tooby 1987; Symons 1987a; 1989]), the development of other mechanisms, including psychological mechanisms, can be confounded by novel environments

\footnotetext{
${ }^{3}$ It is of course legitimate to ascribe phenotypic variance to genes, the environment, or some combination thereof, e.g., a particular individual's skin may be more tanned than mine because he has recently spent more time in the sun, because of genetic differences, or because of some combination of genetic and environmental factors. Note also that finding that a phenotypic difference (e.g., in the suntans of two caucasions) is due solely to environmental factors (e.g., exposure to the sun) does not imply that the expression of such variation can not be an adaptation.

${ }^{4}$ Morphology, physiology, and behavior are aspects of what is simultaneously an entity and a phenomenon, much as light is simultaneously a particle and a wave.
} 
(Betzig 1989, pp. 320-1). This point provides a basis for refuting the charge that it is evolutionarily "sophisticated" to predict the proximate workings of psychological mechanisms, but evolutionarily "naive" to predict reproductive outcomes (see later).

Adaptive By the above definition, an aspect of a phenotype may qualify as an adaptation regardless of whether it currently produces an adaptive or maladaptive outcome-all that is necessary is that a history of selection designed the "trait" to serve a function. Whether that function is currently being served does not matter (see Ruse 1989). In contrast, the term "adaptive" refers strictly to relative (i.e., better versus worse) outcomes. Ultimately, outcomes are judged better or worse according to their effects on gene frequency. Of course, only differences in outcomes that are due to differences in design can direct the evolution of adaptations (Williams 1966, p. 158). Because "inclusive fitness"' theory (Hamilton 1964) provides the most widely accepted basis for keeping track of changes in the frequency of genes underlying adaptations (e.g., Trivers 1985; Williams 1985), an outcome generally is considered adaptive if, relative to other outcomes, it has a more positive effect on inclusive fitness. (In Hamilton's original papers on inclusive fitness, an allele is selected for or against not because of its absolute effect but because of its effect relative to effects of alternative alleles.) Thus, adaptiveness is assessed by comparison, and depending on the specific comparison, a trait either is adaptive or it is not. Accordingly, hypotheses predicting adaptive outcomes are hypotheses that predict that individuals make choices that, given the particular alternatives, maximize their inclusive fitness.

It is difficult to overemphasize the importance of the fact that adaptiveness is a relative concept-i.e., something that can be assessed only in comparison to something else. Thus, for example, when Alexander (1974; 1979) hypothesized that it sometimes is adaptive for men to invest primarily in the offspring of their sisters (under conditions which prevail in about 25 percent of the world's societies), he meant that avuncular investment sometimes can contribute more to a man's inclusive fitness than the more typical arrangement in which parental investment goes primarily to the offspring of a man's mate(s). Alexander's hypothesis does not propose that the avunculate is the best strategy in the best of all imaginable worlds. Furthermore, it may or may not be appropriate to expand his hypothesis by proposing that the avunculate is adaptive relative to still other particular courses of action (e.g., taking steps to increase paternity certainty). If Alexander's hypothesis were to be expanded to address a wider array of alternatives, it would require additional tests (see Gaulin and Schlagel 1980; Flinn 1981), which eventually might allow us to conclude with some confidence that under particular conditions the avunculate maximizes inclusive fitness, relative to all feasible alternative strategies. Thus, it is the process of operationalizing and eventually testing an imagined alternative that converts it into a feasible 
alternative. At present, however, Alexander is only justified in concluding, as he does, that Sahlins (1976) and others are wrong to assert that the avunculate, by its very existence in a large number of societies, precludes the possibility that human kinship can be understood as systems for maximizing inclusive fitness (see Alexander 1988). Moreover, and particularly germane to this paper, refutation of Sahlins' assertion is a first step toward refuting his widely shared assumptions about the nature of the human psyche. An understanding of the psyche, not of the avunculate per se, is what the "fuss" (Symons 1987a) is about. I will have more to say in the final section of this paper about the importance of studies which challenge nonadaptationist constructions (implicit or explicit) of the human psyche. ${ }^{5}$

The foregoing discussion makes the point that hypothesizing that a particular trait yields an adaptive outcome does not imply the belief that the trait is the best of all imaginable alternatives. There are many reasons not to expect perfect adaptation, including factors such as pleiotropy, limited genetic variability, phylogenetic inertia, sampling error, and so on. Thus, notwithstanding the impression that some authors try to convey (e.g., Gould and Lewontin 1979), even the most ardent adaptationists recognize that, in some absolute sense, all organisms fail to maximize inclusive fitness (see Alexander 1987, p. 17). Of course, that organisms fail to maximize inclusive fitness in some absolute sense does not mean that particular behaviors are not adaptive (i.e., inclusive fitness maximizing) in the relativistic sense in which evolutionary biologists usually use the phrase. Thus, acknowledgement of constraints on perfection does not render the adaptationist approach impotent.

Ironically, while critics such as Gould and Lewontin insist that constraints on perfection should make us doubt the efficacy of generating hypotheses which predict adaptive behavior (especially when the hypotheses pertain to humans), others have tried to lead us to a similar conclusion by arguing that behavior almost always is "somewhat adaptive," in the sense that behavior almost always falls short of resulting in suicide and the death of all of one's relatives-the "absolute zero" of adaptiveness. This seems to be Symons' (1989, pp. 140-141) purpose in drawing attention to the obvious fact that "human action is not random with respect to reproduction." His statement implies that studies which claim to support the prediction that a particular behavior is adaptive really only succeed at demonstrating the obvious-that there is a strong bias against acting in ways that approach the absolute zero of adaptiveness. I believe, however, that this type of potential confound-confusing what in an absolute sense is somewhat adaptive behavior for inclusive fitness maximizing behavior (in the sense of Hamilton,

\footnotetext{
${ }^{5}$ I do not mean to imply that the avunculate per se, is unimportant, nor do I mean to imply that understanding it has not been the primary goal of much research. Nevertheless, Sahlins' (1976) book, as well as many other works like it, are as emotionally charged as they are because hypotheses like Alexander's require a human nature that is at odds with the view of human nature that is implicit in many social science writings.
} 
1964) - is primarily a problem for those individuals who, like Symons (1987b; 1989) and Kitcher (1985), advocate an approach for assessing adaptiveness that requires the comparison of actual behavior with an imagined ideal (see later).

In short, whereas some critics question the efficacy of approaches that predict adaptive outcomes by claiming that adaptive behavior is impossible, others do so by claiming that we find adaptive behavior everywhere we look for it. I have argued that both criticisms fail to appreciate that traits are adaptive or maladaptive only in comparison to specific alternatives.

\section{THE RELATIONSHIP BETWEEN AN ADAPTATION AND AN ADAPTIVE OUTCOME}

Biologists generally have recognized that all complex aspects of phenotypes are potentially adaptations (Trivers 1985). This is because phenotypic complexity is not likely to be principally shaped by any evolutionary force other than natural selection (e.g., Dawkins 1986). However, because some complex aspects of phenotypes prove to be epiphenomenal (Williams 1966), that is, analogous to the Spandrels of San Marco (Gould and Lewontin 1979), complexity alone cannot establish that a particular aspect of a phenotype is an adaptation. As indicated in the above definition, it is also necessary to identify evolved function (Williams 1966). An adaptation's evolved function can be identified and understood at many levels (chemical, physiological, psychological, economic/ergonomic, etc.), but, as noted, the ultimate function of an adaptation is gene propagation, usually via inclusive fitness maximization. One implication is that proximate function is always constrained by ultimate function (Dunbar 1982). An example that apprarently applies to all organisms is that, were it not for the necessity of reproducing, design for survival could be improved on (see Williams 1957; Hamilton 1966). It follows that an understanding of ultimate function informs an understanding of at least some proximatc charactcristics of adaptations (Alexander 1990 [this issue]; Betzig 1989). In particular, it is argued throughout much of the remainder of this paper that finding that an adaptation produces an adaptive outcome in particular environments, but not in others, often illuminates the trait's selective background and ontogeny, including the extent to which a trait is general-purpose, and the range of conditions under which such general-purposeness produces adaptive outcomes.

Problems associated with identifying adaptations. In nonhuman organisms, doubt about a trait's status as an adaptation sometimes can be obviated by demonstrating that the trait in question is complex, persistent, and serves a proximate function (e.g., see discussion about the status of lateral lines of fishes [Williams 1966, pp. 10-11]). Such evidence is often convincing, even in the absence of data directly demonstrating reproductive significance, because plausible, nonindividual-selectionist alternatives that can account for 
the evolution of complex, functional nonhuman traits are rare. For example, no one would insist that the lateral lines of fishes have an independent cultural origin. Nonetheless, even for nonhuman organisms, it sometimes is useful to go beyond the identification of proximate function.

Consider dominance hierarchies: less than twenty years ago, Kummer (1971, p. 59) stated, in reference to baboons, that "dominant animals will take the food while the inferior ones will suffer from the shortage . . . [which] seems to be adaptive, because the experienced and reproductively active adult is more valuable to the group than an easily replaceable youngster." Why would few primatologists make such a statement today? One reason is the wider dissemination of the theoretical arguments advanced by Williams (1966). Another is that study after study in species after species indicate that dominant animals use their proximate advantages in ways that have a positive effect on one or more of the components of inclusive fitness. ${ }^{6}$ Similarly, data on the reproductive consequences of traits can call into question any number of nonadaptationist alternative hypotheses (e.g., male dominance is a side effect of something else) such as high levels of testosterone which are needed for proper sexual function; sexual dimorphism is due to phylogenetic inertia and or allometry; and so on) (see Alcock 1987; Sherman 1988, for additional arguments along these lines).

Of course, the rare study which fails to find a positive relationship between dominance and fitness does not necessarily represent a major challenge to Darwinian theory (Symons 1989). Such studies do, however, represent minor challenges, and therefore call for indentification of the factors confounding adaptive outcomes. If a suitable confounding factor cannot be at least tentatively identified (e.g., the dominant male is sterile), an anomaly that begins as minor challenge to Darwinian theory can become a major challenge. The point is that to maintain the claim that a particular trait is an adaptation it is necessary to demonstrate that it functions as designed, or if it does not, to explain why. It is not enough to simply assert that dominance (or anything else) must have been adaptive in the Pleistocene.

As another example, consider female mate choice. Until recently, adaptationist hypotheses about female choice have been thought to be problematic, in the absence of paternal care, because of the belief that choice quickly eliminates its selective rationale by eliminating heritable variability in male quality (e.g., Maynard Smith 1978). However, an empirical study designed to measure reproductive outcomes has been an important source of information leading to the demise of the aforementioned argument (see Partridge 1980). Partridge demonstrated that allowing Drosophila females to choose their mates increased one component of their fitness (offspring survival). Thus, in addition to helping to identify female mate choice as an adaptation,

${ }^{6}$ The assumption that current outcomes will usually accurately reflect past outcomes is justifiable in the absence of specific counter-arguments (e.g., arguments pusiting new selection pressures). 
Partidge's results suggest that the proximate function of female choice in Drosophila is the production of healthier offspring (as opposed to, for example, functioning to produce sexier sons). More recent studies of the fitness effects of various behaviors in Drosophila have yielded additional insights about the selective background of particular Drosophila behaviors, as well as about the proximate function of particular behavioral adaptations (see Hoffmann and Cacoyianni 1989). Of course, studies such as Hoffmann's and Cacoyianni's do not deny that new theory and concomitant predictions about proximate design (e.g., Hamilton and Zuk 1982; Thornhill 1990) also have contributed to our understanding of female choice as an adaptation. Arguments criticizing the study of the design of adaptations (e.g., Wade 1987) are themselves deserving of criticism (e.g., Grafen 1988; Thornhill 1990).

In the face of evidence like the above, it is not surprising that a well entrenched skepticism usually greets calls to abandon studies which seek to identify and explain adaptations in part by measuring fitness and its components (e.g., see Mayr's 1983 rejoinder to Gould and Lewontin's, 1979, critique). Ironically, when humans are the focal animal this skepticism is often absent because most people studying humans believe that learning and culture somehow decouple individuals from their evolved adaptations (e.g., see Durkheim's sui generis view of culture and Dawkin's memes). Thus, it is especially important that studies of humans be designed to indicate whether or not particular learned traits are adaptations.

In humans, evidence of complexity, persistence, and proximate function, by themselves, often are inadequate to indicate an adaptation because culture-even when conceived of as being almost totally independent of a history of natural selection-is also expected to (somehow) produce complex, proximately functional traints. For example, finding that people generally strive to increase their individual wealth would not, in the context of Marxist theory, constitute definitive evidence of a specific adaptation, even though such "economic rationality" is complex, persistent, and proximately functional. Marxism blames the ubiquity of wealth-maximizing behavior on the exportation of capitalism. I suggest, however, that one can refute, or at least demonstrate the incompleteness of, Marxist and other independent cultural theories of behavior by tracing proximate function through to ultimate function. Thus, for example, in regard to the notion of economic rationality, as defined above, the relative efficacy of a Darwinian evolutionary approach can be demonstrated by searching for areas in which economic rationality is expected to conflict with reproductive rationality, such as in dealings with offspring and other relatives (see Turke 1985; 1988; 1989; Betzig 1986, ch. 3). Only from a Darwinian evolutionary perspective are individuals necessarily expected to be designed to disburse resources (wealth) in a manner that maximizes, or at least would have maximized, inclusive fitness. In general, tests calling for the measurement of reproductive outcomes have the power to distinguish between hypotheses that view individual use of culture as comprised of adaptations from those which view 
individual use of culture as somehow largely independent of adaptations (an excellent illustration of this point is found in Gibbs' [1990] study of bird songs). ${ }^{7}$

Although accomplished in numerous instances (e.g., Clutton-Brock 1988), it can be difficult both to determine whether an individual is behaving adaptively and to link an adaptive outcome with a specific adaptation (Grafen 1988). Later, I discuss methods used to determine which (if any) humans behave adaptively. The general point to be made at this time, however, is that any aspect of a phenotype either is an individual-level adaptation or it is not, and it either yields an adaptive outcome in a particular environment or it does not. If the trait in question is an individual-level adaptation, then predictions from the correct adaptationist hypothesis should, once thought of, fare better than predictions from hypotheses holding that the trait is 1) epiphenomenal, 2) a product of random evolutionary forces, 3) a product of forces that are presumed to be independent of organic evolution (as is sometimes thought of culture), or 4) a product of group selection (see Betzig 1989).

In addition, there are two kinds of adaptationist hypotheses that need to be distinguished: those that predict adaptive outcomes and those that do not. Given sufficient environmental continuity, and only then, adaptations are expected to produce adaptive outcomes (e.g., Tingergen 1963; Symons 1979). Thus, there are two possible fates for an adaptationist hypothesis that predicts an adaptive outcome: the prediction obtains and therefore the hypothesis is supported; or the prediction fails and therefore the hypothesis is falsified. However, the failure of a predicted adaptive outcome can occur because the component of the hypothesis referring to sufficient environmental continuity is wrong, or because some other component of the hypothesis is wrong or incomplete. If it is determined that the hypothesis fails for the former reason, light nevertheless is shed on the selective background and ontogeny of the trait that the hypothesis attempts to describe (see later). Failure based on the latter reason should shift the focus of interest to alternative adaptationist and nonadaptationist hypotheses. In any case,

\footnotetext{
${ }^{7}$ By default, most people seem to believe that there is a "biological" basis to human behavior that is somehow overlaid by a cultural (nonbiological) basis to human behavior. This belief is widespread because many people conflate genetics with biology, and thereby conclude it proper to think of biology, which refers to life itself, the products of evolution, as the opposite of phenotypic plasticity, and thus as the opposite of culture (Alexander 1987). It is because of widespread acceptance of this false dichotomy that many pcople dismiss, a priori, an evolutionary approach to the study of learned, cultural behavior. Although dismissal of an evolutionary approach on such grounds is invalid because the grounds themselves are invalid (Daly 1982; Flinn and Alexander 1982; Turke 1984), it is nevertheless possible for culture to have a signiticant independent effect on the human phenotype. In other words, although there is no a priori basis for concluding that learning and culture necessarily decouple human behavior from organic evolution, there also is no a priori basis from which to conclude that learning and culture cannot decouple human behavior from organic evolution. Therefore it is reasonable and necessary to distinguish hypotheses that argue that cultural change and stasis result from a history of interaction by reproductively self-interested individuals (Alexander 1979) with hypotheses arguing that other forces, naturally selected ideas (Cloak 1975; Dawkins 1976), and or cultural transmission rules (Boyd and Richerson 1985), wholly or partly direct the evolution of culture.
} 
though, when predicted adaptive outcomes succeed, adaptationist hypotheses gain support. The reason is that adaptive outcomes are highly orchestrated events, which implies that an incorrect hypothesis is unlikely to correctly predict a specific adaptive outcome. Said another way, there are relatively numerous reasons not to expect a specific trait to produce an adaptive outcome (e.g., random forces, independent cultural evolution, etc.); therefore, a hypothesis that corrrectly predicts an adaptive outcome has a probability of being correct that is greater than chance (see also, Betzig 1989). Thus, for example, finding a positive correlation between reputation for fierceness and mating/reproductive success is evidence favoring the hypothesis that, for Yanomamo males, striving to gain a reputation for fierceness is a faculative adaptation (Chagnon 1988a). Of course, as Chagnon notes, as hypotheses are fine-tuned they generate additional predictions (including about proximate design and function), which, if confirmed, lend increasing confidence.

In short, the appropriateness of studying proximate design does not deny the appropriateness of seeking correlations with reproductive success and its components (Tinbergen 1963; Sherman 1988; Grafen 1988; Betzig 1989). Although correlations do not prove cause, they are suggestive, and they are especially so to the extent that they are predicted by a plausible hypothesis.

Joan Silk's (1980) study of adoption in Oceania can be used to further illustrate some of the foregoing points. Silk, challenged by Sahlins (1976), demonstrated that the high prevalence of adoption in many Oceanic societies conforms to expectations from Hamilton's rule. Specifically, she demonstrated that adoptive parents tend overwhelmingly to be close genetic relatives of the children they adopt and also tend to have few or no dependent children of their own.

The odds that the fit of Silk's data with Hamilton's rule are spurious are low because Hamilton's rule poses stringent requirements relative to the range of possible outcomes, which might be expected on a number of theoretical grounds, including the following 1) adoption may be an epiphenomenal by-product of something else (e.g., maternal instinct gone awry); 2) random evolutionary forces-i.e., not selection-may have significantly influenced the evolution of mechanisms that manifest adoptive behavior; 3 ) adoption may be a product of forces that are presumed to be independent of organic evolution (as is sometimes thought of culture); or 4) group selection may have molded the evolution of mechanisms that manifest adoptive behavior.

What, though, if Silk's study had failed to find that adoption in Oceania conformed to Hamilton's rule? One cogent possibility is that an alternative adaptationist hypothesis explains adoption in Oceania. Perhaps adoption has as much to do with reciprocity or manipulation as it does with nepotism (which, incidentally, has not yet been ruled out but which can be tested by closer scrutiny of instances that appear to contradict, or at least appear not 
to be fully explained by, Hamilton's rule, if such occur [see Betzig 1989; Silk 1990]).

Another possibility is that the environments individuals encounter on Pacific atolls and islands differ so much from the environments of human evolution that adaptations involving child care and other transactions among relatives are off-track. Finding that adoption in Oceania is maladaptive would support this line of argument. A next step would be to seek where breakdown occurs in the ontongeny of behaviors comprising adoption. For example, do the environments of Oceania interfere with the close emotional attachment that usually develops between parents and their offspring? Or does confinement in a small area cause maternal and paternal attachment to be generalized, inappropriately (from the perspective of Hamilton's rule), to children other than their own? As already noted, some evolutionary psychologists, such as Symons, would tend to prefer the second kind of explanation, because it posits that emotional mechanisms develop normally but are misapplied. The first kind of explanation, however, would tend to be ignored because it posits that emotional mechanisms, themselves, develop unusual characteritics, or even fail to develop.

The main point of this section has been to argue that the success or failure of hypotheses predicting adaptive outcomes often imparts much information about adaptations. Nothing has been said, however, to suggest that testing for adaptive outcomes is the only way to gain information about adaptations. Testing for adaptiveness is part of a larger approach (i.e., an approach that would, ideally, focus on all proximate and ultimate aspects of traits), and has strengths and weaknesses that vary with the situation (see Grafen 1988). All too often, in my opinion, the different components of this larger approach have been disparaged by glossing over the difficulties of a favored "sub-approach" while dwelling on the difficulties associated with the sub-approach(es) of one's competitors. Cosmides and Tooby's (1987, p. 284) rationale for focussing study at the level of the psychological mechanism is a case in point. They argue that unlike behavior, psychological mechanisms are "invariant" components of the phenotype (see also Symons 1987a; 1989). However, such a prescription ignores, among other things, the fact that psychological mechanisms are-as much as behavior-aspects of the phenotype and therefore also subject to variation due to environmental change. In this regard, Alexander (1990 [this issue]) and Smuts (1990) have likened the human psyche to the immune system, as being literally built from experience. In general, evolutionary psychologists pay little attention to the findings of neural scientists that demonstrate that the structure of the brain remains plastic at all stages of life. Thus, the hypothesis that human mate choice, for example, should be adaptive in contemporary societies would rest on as sound of a theoretical foundation as the hypothesis that mate choice mechanisms will develop invariantly in contemporary environments (i.e., will develop the same proximate characteristics they would have in the Pleistocene) (cf. Symons 1979; Buss 1989). It may be, however, that if 
humans in some contemporary societies fail to choose mates adaptively it is because mechanisms have developed abnormally. It seems to me, though, that, notwithstanding the potentially disruptive effect of environmental novelty, because long-term directional and stabilizing selection are widely evident in all forms of life, it generally is reasonable to at least consider hypotheses that hold that the mechanisms underlying behavior, as well as the behavior itself, will develop in a manner that leads to adaptive outcomes.

\section{Prospects for Adaptive Human Behavior Outside the Pleistocene}

John Tooby and Leda Cosmides $(1989$, p. 35) are of the opinion that since the end of the Pleistocene cultural change has been too fast to expect people to adjust adaptively; they acknowledge, however, that the human psyche must have been up to the task of making adaptive adjustments to the cultural environments of the Pleistocene or else full-blown capacity for culture would not have evolved (see also Symons 1979; 1987; Cosmides and Tooby 1987). These are empirical questions. However, even in terms of theory there is no firm basis for the opinion that cultural change was not too rapid before some people became sedentary and grew plants, but necessarily too rapid afterwards. ${ }^{8}$ What, in particular, is especially disruptive about becoming more sedentary and subsisting increasingly on domesticated plants and animals? Is it accompanying changes in technology, social organization, ideology, or combinations thereof? How much, when, where, and how fast did changes occur in each of these cultural realms, and how much do quantitative answers to these questions matter? Unfortunately, a theoretical basis for answering the preceding questions in inadequate largely because of uncertainty about the problems past environments imposed on hominids, and about the range of solutions that were employed (Smuts 1990).

Cosmides, Symons, Tooby, and many others have largely bypassed the above issues by viewing the Pleistocene as a relatively featureless monolith, a constant that became suddenly complex and subject to rapid change only about 12,000 years ago (Alexander 1990). This simplistic view misleads them into believing that theirs is a thorough, widely agreed upon, understanding of how humans adapted to the environments of the Pleistocene, which in turn misleads them into believing that there is a well-developed foundation for the assertion that adaptive behavior is not to be expected outside the Pleistocene. It is, nevertheless, undeniable that information about the probIcms humans faced in the Plcistocene should be used in the generation of hypotheses about human design and behavior (see Alexander and Noonan 1979 , for an example of this kind of "strategic modeling"), as should problems faced during the 500 generations of the past 10,000 years. However,

${ }^{8}$ This takes an old theme-a priori, culture leads us off-track-and gives it a new twist: a priori, agriculture leads us off-track (Betzig pers. comm.). 
as Smuts (1990) notes, information from the Pleistocene often is not well established, and often is not available in sufficient detail, to make this step in hypothesis generation as immediately informative as is implied in Cosmides and Tooby's (1987, pp. 302-303) six-step formulation of the evolutionary approach. Thus, in other words, although Cosmides and Tooby correctly outline the elements of an evolutionary approach, their insistence on a specific ordering of these elements is often impractical. What happens in the present informs our understanding of what happened in the past at least as much as vice versa, if for no other reasons than that the present is more visible and more subject to experimentation. A particularly relevant example is that evidence that people behave adaptively in environments which are, in some respects, very different from those of hunter-gatherers (see latter) suggests that environmental features unique to hunter-gathers had little role in shaping human evolution. In turn, in reconstructing our evolutionary history we should know not to emphasize selection pressures unique to huntergatherers. ${ }^{9}$

In some respects Cosmides et al. are justified in assuming that the Pleistocene was relatively simple and constant. People apparently hunted and gathered throughout, albeit they did so in somewhat different ways at different times and in different places (Lee and Devore 1968). However, as alluded to previously, foraging problems may not have been (at least not directly) the primary selective pressures that shaped the evolution of the human psyche. A cogent alternative hypothesis is that social competition for status, and cultural currencies related to status, such as fashion, demonstration of verbal and physical skills, and so on, primarily shaped the evolution of the human psyche (Humphrey 1976; Alexander 1987; 1989). In the light of this latter hypothesis - that is, if the primary function of the psyche was cultural, social competition, and if this pysche, as such, was fully evolved (or nearly so) before the end of the Pleistocene-it is probable (or at least not beyond consideration) that the cultural, social environments of the Pleistocene were about as complex and likely to contain novelty as present-day cultural, social environments. It may be, therefore, that we continue to this day to use our brain for the primary proximate purpose for which it evolved (Alexander 1990; Turke 1989, p. 63), thus contesting the assertion that "There is no reason to suppose that any specific modern cultural practice is adaptive", (Tooby and Cosmides 1989, p. 35; sce also Symons 1979; 1989).

The foregoing arguments indicate that scholars with similar views of how evolution works, nevertheless have somewhat different (or more or less developed) views of what constituted the important selective pressures during human evolution (e.g., emphasis on problems specifically and directly

\footnotetext{
${ }^{9}$ In terms of Cosmides and Tooby's (1987) schema, this represents the use of tests of current adaptiveness to inform step 2, which pertains to understanding the selection pressures responsible for molding the evolution of the human psyche.
} 
related to foraging versus emphasis on social problems that remain cogent under many other subsistence regimens). These differences lead to alternative hypotheses about the nature of the human psyche (see later). Discovering the circumstances under which people do or do not behave adaptively in the range of contemporary environments is an important step toward testing the validity of each of these alternatives.

\title{
GENERAL PURPOSE PSYCHOLOGICAL MECHANISMS
}

In explicating their hypothesis of the nature of the human psyche, Tooby and Cosmides (1989) have attempted to draw a parallel between the approach of some behaviorists in the field of psychology with the approach of a particular group of anthropologists and biologists. They state:

\begin{abstract}
Not only have social scientists been all too inclined to think of the mind as a general purpose computer, but even evolutionarily informed scholars have been susceptible to a similar species of error: instead of a general learning mechanism, evolutionary biologists have used the concept of the psyche which operates "as if" it were an inclusive fitness maximizer. Not only is this hypothetical entity impossible even in principle (Cosmides and Tooby 1987), but as a conceptual tool it has interferred with productive research directions (pp. 31-32).
\end{abstract}

Symons (1987a; 1989) and Kitcher (1985) have argued along similar lines. The point to be made here, however, is that in one important sense Tooby and Cosmides (as well as probably Symons and Kitcher) apparently also believe that the human psyche does operate as if it were an inclusive fitness maximizer. That is, they believe that "the psyche is almost certainly comprised of a multitude of domain-specific, special-purpose adaptive mechanisms, organized into a coevolved, highly intricate architecture" (Tooby and Cosmides 1989 , p. 31, emphasis added), and they of course would also recognize that by another name this highly intricate architecture is an adaptation-an evolved mechanism with the evolved function of coordinating other mechanisms in a manner that maximizes inclusive fitness. When the anthropologists and biologists who are being criticized (Alexander, Betzig, Chagnon, Crook and Crook, Dickemann, Irons, and Turke have been singled out in the articles referred to earlier) hypothesize as if the human psyche operates as an inclusive fitness maximizer, they have in mind exactly this kind of mechanism or "architecture." Moreover, that evolution "has produced a conscious striving for intermediate goals-such as a good diet or sexual satisfaction" (Irons 1983, p. 200)-is an insight that did not have to wait for Symons (1989, p. 140). Thus, it is false to imply that Alexander et al. believe that the so-called "inclusive fitness maximizer"' is not comprised of proximate mechanisms (molecular, physiological, and psychological) that generate specific proximate goals that somehow are weighted and coordi- 
nated (see Alexander 1979, ch. 3, for numerous examples). ${ }^{10}$ With the exception of some outdated behaviorists (which unfortunately includes much of modern-day psychology [Leda Cosmides, personal communication]), we all have been working toward understanding the nature of the more and less specific mechanisms that constitute the human psyche. The debate is about how to proceed. ${ }^{11}$

Symons has asserted that we will not learn anything about mechanisms, or much about anything else, by focusing on reproductive outcomes in contemporary environments (see, for example, a list of propositions which Symons [1989, p. 139] claims are not illuminated by Betzig's [1988a] study of reproductive outcomes on Ifaluk Atoll). Barkow (1984) and Tooby and Cosmides (1989) seem to share this view. I suggest, though, that the reason for this conclusion on the part of Symons et al. is that they begin with the assumption that the mechanisms that constitute the psyche are too specific to expect adaptive behavior outside the Pleistocene. In other words, they seem to deny the possibility that the design of the human psyche is flexible enough (i.e., designed to cope with a specific range of novel social conditions) to produce adaptive behavior in contemporary environments. By ignoring, or deeming irrelevant, studies that actually measure reproductive outcomes, their argument is reduced to tautology: the psyche must be designed to overcome specific problems that are, in some crucial respect, unique to the Pleistocene because humans behave maladaptively outside the Pleistocene, and humans must behave maladaptively outside the Pleistocene because their psyches are designed to overcome specific problems that are, in some crucial respect, unique to the Pleistocene.

A theoretical basis for characterizing the human psyche as relatively (but not infinitely) general purpose (i.e., flexible enough to deal with a fair amount of novelty) recently has been made explicit in two papers by Alexander $(1989 ; 1990)$. Alexander's hypothesis, in essence, is that conciousness-through providing an ability to produce scenarios in a way that coordinates information from other, often more specific mechanisms (or

\footnotetext{
${ }^{10}$ Symons (1989, p. 140) seems to be arguing that so-called Darwinian anthropologists are unaware that proximate goals underly ultimate goals, which, if believed, would suggest that the focus by Darwinian anthropologists on ultimate goals cannot be related to the illumination of proximate goals and their underlying mechanisms.

${ }^{11}$ Although we all are interested in understanding human nature, some more than others have been interested, at least in specific instances, in understanding human nature not as an end in of itself but in order to better understand specific phenomena (e.g., despotism, demographic transition, warfare, moral systems). Of course, a large number of mechanisms probably underly the behaviors resulting in despotism, demographic transition, and other complex phenomena. Thus, there is justification for studying these phenomena other than by a piecemeal study of mechanisms. Moreover, even relatively simple phenomena such as status-linked female infanticide (e.g., Dickemann 1979) are likely to be played out by numerous, complexly interacting mechanisms, including consciousness. This contrasts starkly, however, with the specific and in my opinion overly simplistic psychological argument Barkow (1984) offers as the missing link in Dickemann's hypothesis about infanticide. If it were as simple as Barkow suggests to correctly fill in the proximate, psychological, mechanistic details of hypotheses like Dickemann's, Dickemann certainly would be remiss in not doing so. As it is, Barkow has not supplied a constructive critique.
} 
algorithms, epigenetic rules, rules of thumb, etc.)-evolved to deal with the range of novel social conditions that culture-bearing individuals have been generating ever since the first glimmerings of culture. Said another way, social novelty was a primary selective pressure in the Pleistocene, consciousness is one of the mental organs that evolved to cope with social novelty, and therefore we should not assume that social novelty in contemporary environments necessarily outstrips the ability of the human psyche to generate adaptive strategies.

In the light of the foregoing hypothesis, let us now examine the arguments Symons has advanced in regard to the study of adaptation and adaptiveness in contemporary environments. In a discussion of cross cousin marriage Symons (1989, p. 135) states that "unless at least one mechanism owes its form to the differential reproductive success of individuals who did or did not marry cross cousins in ancestral populations-cross cousin marriage per se is not a Darwinian adaptation." His implication is that there is no such mechanism, and therefore determining whether cross-cousin marriage is manifested adaptively is a bankrupt enterprise. Symons (1989, pp. 1389) argues similarly against Crook and Crook's (1988) attempt to demonstrate that polyandry may be adaptive in particular Tibetan environments. He notes that particular contingencies in the current Tietan environment, such as land shortages, primogenitor, and taxation, did not exist in the Pleistocene, and he suggests therefore that there could not have been selection for the specific mechanisms that are implied by Crook and Crook's hypothesis. In other words, Symons believes that no specific mechanism evolved to cope with the specific problems that cross-cousin marriage and polyandry are hypothesized to solve.

However, as noted earlier, consciousness, in interaction with other components of the psyche, such as cognitive ability, may be just such a mechanism. Arguing specifically against Symons' polyandry example, Alexander (1990 [this issue]; see also Betzig 1989, pp. 318-9) hypothesizes 1) that consciousness, through building and choosing between scenarios that somehow coordinate other more specific algorithms (e.g., algorithms attributing positive value to achieving status and having sex), evolved to deal with a range of novel social conditions that were present long before the end of the Pleistocene; and 2) the novelty of particular contingencies pertaining to mating and marriage in present day Tibet may well be within this range. ${ }^{12}$

It is important to recognize that because Symons believes he has made a valid first-principles kind of argument against the hypothesis that polyandry represents an evolved adaptive strategy, he sees no purpose in determining

12 Dawkins (1982, pp. 27-28) has presented an argument pertaining to human polyandry that, as Symons notes, closely resembles his own. However, as I have noted (Turke 1984), Dawkins also considers a possibility that is more akin to Alexander's hypothesis. That is, after presenting the argument which Symons claims supports his own, Dawkins states, "or natural selection had to have favored the universal occurrence of genes programming some complex "conditional strategy"." Symons fails to mention this. 
whether contemporary peoples consistently make adaptive decisions about how and when to marry polyandrously. The alternative that I am advocating is that 1) throughout human evolutionary history establishing a relationship between a man and a woman and their kin has been a social problem involving the assessment and manipulation of, among other things, status and resources; 2) mechanisms (e.g., consciousness, cognitive ability) evolved to coordinate solutions to these problems; and therefore 3) unless marriage in Tibet involves something more novel than the assessment and manipulation of status and resources, marriage patterns in post-Pleistocene Tibet are expected to be adaptive. If we find that they are adaptive, support is given to this view of mechanisms and to this view of what marriage is a solution to. If we find maladaption, this view of mechanisms and what marriage is a solution to is questioned. In either case, however, additional research, especially research focussing on proximate design (which Cosmides, Symons, Tooby, and others appropriately advocate), would be required to complete our understanding of the psychological mechanisms underlying the behaviors in question.

The foregoing debate centers on disagreement over the specificity of psychological mechanisms. Two points bear emphasizing: 1) Many hypotheses derived by Alexander et al. seem to require that some mechanisms of the human psyche are relatively general-purpose; Symons, in particular, appears to deny such a possibility (however both Alexander and Symons view the psyche as much more specific-purpose than theorists who view the psyche as a blank slate). Thus, Symons might argue, for example, that although stepping out of the way of a fast moving truck is fitness enhancing, none of the neural mechanisms that people possess have been designed directly to achieve that end: trucks were not present in the Pleistocene. The alternative view, however, is that Symons et al. sometimes get the level of specificity wrong, and the tendency has been to err in the direction of being overly specific. In this case, humans may have evolved neural mechanisms that have been designed specifically to achieve the end of avoiding heavy, fast moving objects; whether they happen to be rhinoceri or trucks is largely irrelevant. (I say largely because people probably are poor judges of how much time they should allow to step out of the way of heavy objects that move more than twice as fast as rhinoceri, at least until they have used consciousness, cognition, and perhaps other relatively general-purpose mental mechanisms to acquire what may be referred to as indirect experience).

2) It should be clear by now that "mechanisms" are integral to arguments suggesting that the human psyche is in some ways general purposealbeit much remains to be known about the mechanistic details underlying this general purposeness. Thus, it is an overstatement to assert, as more than one of my colleagues has, that the human mind as characterized by socalled "Darwinian anthropologists" resembles a chess-playing computer program that says nothing more than "win." Mistaking an interest in who wins (i.e., behaves adaptively) for a lack of interest in evolved mechanisms 
is an error that follows from a failure to recognize that knowing how adaptive outcomes correlate with environmental variation contributes to an understanding of the nature of mechanisms.

In sum, if social competition was a primary selective pressure throughout human evolution, and consciousness evolved largely as a result of this pressure, then Cosmides, Symons, and Tooby (and Durkheim, Sahlins, et al.) are premature in their conviction that the psyche is such that we should not expect to find adaptive tracking of the environment by people in contemporary societies. How do we decide between these alternative views? Empirically, by determining which people in the wide range of present-day, post-Pleistocene environments are behaving adaptively and which are not. This work has begun, and is summarized in the following.

\section{WHICH HUMANS BEHAVE ADAPTIVELY?}

Two approaches have been used to assess whether or not contemporary peoples behave adaptively. Kitcher (1985) and Symons (1987b) have been the primary advocates of the first of these approaches (hereafter the KitcherSymons approach). It seems to me, however, that many scholars have speculated along similar lines, thus perhaps accounting for the widespread conclusion that human behavior is off-track (see Turke 1989, pp. 62-63).

Symons $(1989$, p. 140) proposes that we "compare the actions of ethnographic subjects with an imaginary social engineer's ideal design for fitness maximizing actions." He then cites Kitcher's (1985) critique of Dickemann's (1979) hypothesis which argues, among other things, that female infanticide in upper caste India is adaptive from the perspective of the perpetrators. Kitcher asserts that such infanticide is not adaptive because more fitness would accrue to parents who instead of killing their daughters provided them with wet nurses. The problem with this approach is that if the ideal social engineer (Kitcher!) leaves out even one constraint, the whole exercise may be for naught. For example, Alexander (1988) points out that as soon as one recognizes that wet nurses are not free of charge, or that a daughter's presence can decrease the status of her entire family (which are just two of many potential constraints Kitcher ignores), one has the beginning of a basis for doubting that hiring a wet nurse is adaptive relative to infanticide.

Many others have tried to play the role of ideal social engineer: Symons (1987b) avers that wealthy men in Western societies would buy islands and build harems on them, if they were truly behaving adaptively. However, no man is an island. What if, as has been hypothesized (Alexander 1974; 1987; Betzig 1986), behaviors that tend to have the effect of leveling reproductive opportunities constitute strategies that have been, and perhaps continue to be, adaptive in environments subject to specific kinds of escalating social competition (see Turke 1989, pp. 82-85)?

Similarly, Symons suggests that men should strive to be frequent donors at sperm banks; and that white women, because their babies currently are 
in demand on the adoption market, should strive to take advantage of that market. What, though, are the potential constraints? I personally do not have immediate access to a sperm bank (or if I do, I don't know about it). I presumably could enter medical school and thereby gain access, but would the costs exceed the benefits? Just how many sperm donors actually sire children? All of them? One out of a thousand? Moreover, a strong motivation to donate at sperm banks may require, given the recentness of their invention, that desire to maximize reproductive success be brought into the conscious. However, has likelihood of a conscious desire to maximize reproductive success been suppressed by selection because it produced offsetting social handicaps? Cogent arguments have been given for keeping related "selfish" motivations out of the conscious (see Alexander 1987). In regard to the adoption scenario, what unknown costs might be associated with psyches which have been designed so that they feel that bearing babies and giving them up for adoption is a positive experience? How would potential nepotists and reciprocators react on learning that a particular woman is bearing children only to give them up for adoption? Symons must at least begin to ask such questions before jumping to the conclusion that individuals who fail to act on his scenarios are behaving maladaptively.

Tooby and Cosmides (1989, p. 35), in explicitily advocating the KitcherSymons approach, state that "The initiation or voluntary participation in modern war games by Germans, Japanese, Russians, North Koreans, Cambodians, Argentinians, Iraquis, or Americans, or their elites, do not seem to have enhanced the fitness of those involved." Their list, of course, is of countries in which many young men recently have died for a losing cause. But surely, even in the Pleistocene-when according to Tooby and Cosmides behavior was still adaptive-people died for losing causes. In other words, even in the Pleistocene people certainly behaved in ways that sometimes failed to pay off, just as nonhuman organisms do even in undisturbed environments. The point is that evidence that individuals take calculated risks is not a sufficient basis for labelling the species as off-track. Tooby and Cosmides must have something else in mind in so labelling contemporary humans, and although they might prove to be right their evidence is not sufficient for their claim. What, then, is their point? Certainly they realize that the effects of fighting on population fitness (i.e., group fitness) are probably irrelevant. Moreover, with regard to what they refer to as "voluntary particpation," if one considers the likely fate of young German men, for example, who did not give the impression of voluntarily joining Hitler's army, it is far from clear that such volunteerism is indeed individually maladaptive.

Barkow (1989, p. 116) presents the centuries old practice of "cupping" (or "bleeding") as an example of an unequivocally maladaptive cultural trait. In other words, he assumes that cupping would not be part of an ideal social engineer's plan. Ironically, on the day I read Barkow's claim I also happened to read papers by Kluger (1978) and Weinberg (1984) presenting evidence 
indicating that, in combination with fever, iron depletion-which according to Kluger can be facilitated by cupping-has evolved in many species, including humans, as an effective response to bacterial infection. In any case, even if it is wrong to suggest that cupping sometimes benefits patients, if patients can be convinced to pay for the procedure it may well be adaptive for physicians to do it. Manipulation of just this sort is widespread in nature (e.g., Dawkins 1982).

The larger issue is that Barkow (1989) has left the mainstream of evolutionary theory by divorcing the individual from the concept of adaptiveness. He is concerned with traits or information being adaptive or maladaptive to society or culture. ${ }^{13}$ (As Alexander [1988] and Maynard Smith [1988] note, Kitcher [1985] errs similarly by giving significance to traits lowering mean population fitness.) However, adaptiveness is a concept that should be judged in the currency of relative effect on individual (inclusive) fitness; and making the best of a bad situation is adaptive. In other words, most evolutionary biologists agree that it matters little, or not at all, that the average fitness of the group (or culture or society) is reduced; and it matters little, or not at all, that fitness is reduced on some kind of absolute scale.

In short, it is difficult to know if an imagined behavioral strategy is really more adaptive than actual strategies because it is difficult to also imagine all the constraints that would apply. Kitcher et al. stop short of considering even the most obvious constraints, perhaps because their "empirical approach" is actually little more than an afterthought founded on the a priori theoretical conviction that human behavior must be maladaptive outside the Pleistocene (see above).

The failure to think hard about how particular behaviors of modern humans might be adaptive is reminiscent of some late nineteenth and early twentieth century naturalists who were ready to reject Darwinism, or at least severely restrict its scope, because as Gould (1977) notes (in his essay on the huge antlers of Irish elk) they were too ready to believe that it would be impossible to account for many of the unique and unusual features of organisms in terms of individual reproductive advantage. Thus, it seems that the Kitcher-Symons approach would easily, but wrongly, attribute maladaptive behavior to all kinds of animals. Sockeye salmon (Oncorhynchus nerka), for example, go to a lot of trouble to return to their place of birth to spawn, and, as far as I know, no one has thought of a good adaptive explanation for his behavior. Nevertheless, one suspects that few biologists therefore believe that salmon behave maladaptively; rather, Inost probably believe that the correct hypothesis has not been thought of. Thus, although

${ }^{13}$ Being out of the mainstream does not make an argument wrong. However, to argue as Barkow does it is necessary to develop, or at least cite, carefully derived models that explicate how it is possible that cultural group selection may be important in human evolution (see Boyd and Richerson 1985). 
more and better empirical studies are needed, there is an even greater need for more and better hypotheses (Alexander personal communication). ${ }^{14}$

A second approach that has been widely used to assess adaptiveness is in some ways exactly the opposite of that advocated by Kitcher and Symons. This approach involves focusing on actual traits, with actual constraints, to derive and test hypotheses that can potentially account for how the traits in question are (or were) adaptive. Alexander (1988) emphasizes that it is especially important to derive this kind of adaptationist hypothesis for traits that seem to be the most difficult to describe in adaptive terms (e.g., the avunculate, moral behavior, Irish elk antlers). Thus, instead of attempting to imagine strategies that would be more adaptive than, say, female infanticide in upper caste India, the idea is to hypothesize how infanticide might be adaptive in upper caste India and then attempt to falsify the hypothesis by deriving testable predictions that must follow if the hypothesis is correct.

This approach may or may not involve the measurement of reproductive differentials (i.e., estimates of inclusive fitness). In the case of infanticide in India, it would be appropriate to model reproductive outcomes that occur from variable levels of infanticide, which potentially could rule out the possibility that infanticide is ever adaptive, but it generally would be inappropriate to compare the reproductive success of actual individuals who do and do not commit infanticide. The reason is that models are always simplifications of reality and therefore, unlike for real individuals, constraints can be readily controlled. Thus, the comparative method as employed by Dickemann provides a better test of her hypothesis than could reasonably be expected of a test that compared reproductive outcomes. There are many similar examples of comparative tests that do not require the measurement of reproductive differentials, many of which have been recently reviewed or presented for the first time in Betzig, Borgerhoff Mulder, and Turke (1988).

Still other hypotheses, although logically identical to Dickemann's, require the measurement of reproductive outcomes. For example, consider the argument that individuals, as a result of their evolved design, generate and use culture adaptively. Irons $(1976 ; 1979 ; 1980)$ was the first to explicitly frame this hypothesis, and he was also the first to test it with demographic data (see also Alexander 1979; Chagnon 1979). This hypothesis predicts a positive relationship between wealth, status, and inclusive fitness (or, more precisely, between power and inclusive fitness), and therefore obviously can be tested by studies which estimate individual inclusive fitness. The basis of this prediction is that the availability of resources limits reproduction (see

\footnotetext{
14 As Williams (1966) correctly notes, some adaptations can be recognized as such by reference to principles of engineering, e.g., the same engineering principles that make birds fly also make airplanes fly. My point, though, is that you cannot assess adaptiveness (as opposed to assessing whether a trait is an adaptation) by comparison with an ideal derived from engineering principles because single traits often are compromised by the requirements of other traits, ultimately in the interests of reproduction (e.g., there is reason to believe that birds would fly even better than they do if their effort were devoted solely to flying).
} 
Turke 1989). Moment by moment individuals are faced with a series of social and economic options. Particular options will be adaptive relative to others, and therefore if individuals regularly choose adaptively, a positive relationship should result between wealth, status, and inclusive fitness. On the other hand, no relationship is expected if environmental novelty, independent cultural evolution, and or group selection are important factors. ${ }^{15}$

Traditional societies The relationship between wealth, status, and inclusive fitness in traditional (i.e., kinship) societies has been the subject of more than a dozen studies (reviewed in Betzig 1988, pp. 5-6). In all, well over one hundred societies have been examined, yielding zero instances in which the relationship is not positive. Here, two studies, the broadest and the most in-depth, will be briefly discussed.

Laura Betzig (1986) examined a standard cross cultural sample (Murdock and White 1969) of 104 politically autonomous traditional societies and found that without exception male status, which she defines in terms of ability to win conflicts of interest, was postively related to number of wives and or concubines. However, because of its breadth, her study stops short of actually measuring inclusive fitness or even reproductive success. She does, though, show that high status males, in addition to having greater access to mates, have more resources to invest in offspring and are better able to prevent cuckoldry. Until someone demonstrates that men with two or more wives (sometimes thousands more) generally have fewer surviving offspring than men with zero or one wife, it is safe to conclude that Betzig's study lends broad-based support to the predicted relationship between wealth, status, and inclusive fitness.

In sacrificing breadth for depth, Monique Borgerhoff Mulder's (1987a,b) study of the relationship between wealth and lifetime reproductive success among the Kipsigis of Kenya comes close to actually measuring inclusive fitness. Her study also is exemplary in that she focuses on both males and females, finding in both cases that there is a positive relationship between wealth and lifetime reproductive success. For males, polygyny is the major causal factor; however, because the relationship between wealth and lifetime reproductive success is also positive for females, it is clear that polygamy is not a necessary cause (see also Turke and Betzig 1985).

Thus, in sum, a careful but as yet incomplete examination of the relationship between wealth, status, and inclusive fitness in over 100 traditional societies yields no grounds for rejecting the hypothesis in question. In other words, individuals in traditional societies appear to use culture adaptively. One implication is that the human psyche is relatively general-purpose, in

${ }^{15}$ Of course, finding a positive relationship does not prove that individuals behave adaptively. Even given a positive relationship, there is room for maladaptive behavior to be occurring. Nevertheless, the hypothesis is falsified by a failure to confirm the predicted relationship. Unfortunately, confirming or disconfirming the prediction is not always straightforward, as is illustrated below in the text. 
the sense of having been designed to deal with a range of social novelties, which is inclusive of the cultural complexities in most or all contemporary traditional societies. Another implication is that hypotheses about pyschological mechanisms should not be derived in reference to selection pressures that are unique to Pleistocene hunter-gatherers. Some of the most relevant selective pressures are likely to include social and cultural problems pertaining to status (e.g., Alexander 1979; Irons 1979b; Betzig 1986; Turke 1989), and there is no reason to believe that the past 500 generations of selection (post-Pleistocene) have not had as much effect as the $\mathbf{5 0 0}$ hundred which preceded them.

Nontraditional societies Economic-minded demographers and demographicminded economists also have been interested in the relationship between wealth, status, and reproduction. It has often been suggested that if children can be considered "normal goods," then, as for other normal goods, people with more resources should have a consumption advantage over people with fewer resources (e.g., Becker 1960). This idea been modified and tested by dozens of economists and demographers in dozens of societies, which in the demographic literature are referred to as more and less developed countires (MDC's and LDC's). Almost without exception, the extent of development (or "'modernization," see Easterlin 1978) even in LDC's is greater than in the traditional societies studied by anthropologists such as Betzig and Borgerhoff Mulder (see above). A large proportion of these studies have been reviewed recently by Mueller and Short (1983).

First, Mueller and Short review what are referred to as "macrolevel studies that relate measures of income to measures of fertility in a multivariate context" (p. 606). In 22 multinational studies involving both LDC's and MDC's they find that the relationship between income and fertility is statistically significant and positive in 4 cases, positive but not significant (or significance was not tested) in 16 cases, significant and negative in 10 cases, and negative but not significant (or significance was not tested) in 11 cases (cases exceed the number of studies because some studies conduct more than one test). The sample size of the individual studies that were reviewed range from 10 geographic regions in Greece to $82 \mathrm{MDC}$ 's and LDC's; countries include, among many others, Chile, India, and Mexico.

In what are referred to as "household" or "microlevel" studies ( $\mathrm{n}=$ 17) the relationship in LDC's between wealth (income) and fertility is positive and significant in 16 cases, positive but not significant (or significance was not tested) in 11 cases, negative and significant in 6 cases, and negative and not significant (or significance was not tested) in 15 cases (cases exceed the number of studies because some studies conduct more than one test). Samples ranged in size from 150 farms in Nepal to 8434 households in the Philipines.

Finally, Mueller and Short review studies of "the asset-fertility relation in LDC's"' (assets are livestock, farm size, land quality, etc). Of 13 studies, 
the relationship between assets and fertility is positive and significant in 10 cases, positive but not significant (or significance was not tested) in 4 cases, negative and significant in 2 cases, and negative but not significant (or significance was not tested) in 5 cases (again, cases exceed the number of studies because some studies conduct more than one test).

Mueller and Short argue that all of the studies they reviewed suffer from significant methodological difficulties, but they conclude that a positive relationship between wealth and fertility gets increasingly difficult to find as the focus of study shifts to more technologically advanced societies. Such a trend becomes even more apparent, I suggest, by the inclusion of analyses from traditional societies which, as shown, always yield a positive relationship between wealth, status, and reproduction. The conclusion I draw from the above data is that, although there is a firm basis for believing that people in traditional contemporary societies track their environments adaptively, the jury is still out with regard to people in more developed contemporary societies. One major obstacle standing in the way of a firmer conclusion is that demographers and economists have been concerned with fertility, not inclusive fitness. In any case, it should be clear by now that the claim that people long ago stopped behaving adaptively rests on a less than solid foundation even when directed at people living in relatively developed societies.

What about the most technologically developed societies? Unfortunately, again, a definitive conclusion is not possible. Some studies, such as Vining's (1986), suggest a weak negative relationship between wealth and inclusive fitness; others, such as Essock-Vitale's (1984), suggest a weak positive relationship; and still others, such as Freedman and Thornton's (1982) suggest that no relationship exists between wealth and inclusive fitness. Of these three studies, Vining's has been severely criticized on both methodological and theoretical grounds (e.g., Daly and Wilson 1986; Gaulin 1986; Irons 1986; Kaplan and Hill 1986; Kurland 1986; Flinn 1987). Nevertheless, Vining's study is often cited (in my experience, usually by anonymous referees) as definitive proof of maladaptive behavior in technologically advanced societies. Essock-Vitale's study is noteworthy not so much for evidence suggesting that very wealthy U.S. women have more surviving children than U.S. women of average wealth, but for demonstrating that this difference is small-smaller than, for example, the difference Borgerhoff Mulder found in her comparison of poor and wealthy Kipsigis women (cited previously). Freedman and Thornton's study is noteworthy (but nonetheless typical of demographic studies) in that it illustrates what can go wrong when research is conducted in an evolutionary theoretical vacuum. Specifically, in their massive longitudal study of the relationship between wealth and fertility in present-day Detroit, Freedman and Thornton eliminated from their analyses individuals who did not marry and those who marricd more than once. However, if the poor marry less often than the wealthy (e.g., because they are less attractive as potential mates, are more frequently incarcerated, or are more likely to have died before reaching marriagable age), 
and if the wealthy (especially males) remarry more often than the poor, it is not surprising that Freedman and Thornton's study fails to tell us anything definitive about the adaptiveness of behavior in technologically advanced societies.

Reference groups The hypothesis from economic theory that the wealthy should be able to afford, and therefore have, more children (see aforementioned) has sometimes been refined in accordance with the observation that individuals usually 1) do not behave as though they are competing equally with everyone and 2) do not define success in absolute terms. Rather, individuals appear to compete within "reference groups" (Frank 1985). For example, evidence suggests that workers in factory " $A$ " will be more concerned with changes in the wages of their coworkers than changes in the wages of workers in factory "B;" similarly, a worker who gets a five dollar raise when his coworkers get a $\mathbf{1 0}$ dollar raise generally is not happy with what in absolute terms is an improvement (Frank 1985).

As Frank notes, the fact that competition often is most intense within reference groups may have much to do with the fact that people lived in small groups that interacted with only a few other small groups throughout most of human evolutionary history. This suggests that modern-day reference groups should be expected to consist primarily of individuals with whom one frequently interacts, such as family, coworkers, and neighbors, albeit the mass media and the mobility made possible by modern technology complicate the notion of reference groups and make them less tractable entities.

In demographic studies, different approaches have been used to take into account the perspective that people make social, economic, and reproductive decisions in reference to members of a specific group or groups. The most well known of these is the relative income approach (Easterlin 1978), in which the effect of wealth on an individual's fertility is evaluated by comparison to the wealth of his (or her) parents, himself at a younger age, or to individuals in the same occupation, ethnic group, social class, and so on. These studies, which have focused almost exclusively on groups within technologically advanced societies, yield more consistently positive results than studies such as Vining's which pay no heed to the concept of reference groups (see also Freedman 1963; Easterlin 1980; Johnston and Lean 1985; Hill and Hill).

Two points pertaining to the notion of reference groups remain to be discussed. The first is that, with the exception of Frank's (1985) analysis of economic (but not reproductive) competition, facts and theories of human evolution have not been considerations in determining who is expected to constitute a particular individual's reference group. Moreover, the economists and demographers who have employed Easterlin's relative income approach have been interested in fertility, not inclusive fitness. Thus, there 
is room for improvement in employing the concept of reference groups in the analysis of the relationship between wealth, status, and inclusive fitness.

Second, paying attention to the concept of reference groups is reasonable, in evolutionary terms, in so far as decisions about the distribution of parental resources, which ultimately determine offspring quality and quantity, depend on how others are distributing such resources. In other words, given that social competition within and between small groups has been the primary force driving human evolution (Alexander 1989; and see the aforementioned), it would have been adaptive during evolutionary history to make social, economic, and reproductive decisions in reference to the individuals with whom one interacts (competitively) and with whom one's immediate descendants are likely to interact. Given such, one can then argue about whether the continuation of such behavior in contemporary societies is adaptive or maladaptive (i.e., on-track or off-track).

To illustrate how maladaptive behavior can arise through making decisions based on the actions of, say, one's occupational reference group, consider a hypothetical cohort of children born in the U.S. in 1955. Suppose that on average 2.0 surviving children had been produced by 1990 by the individuals of the 1955 cohort who had become physicians, and that on average 2.2 surviving children had been produced by 1990 by the individuals who had become clerks. If the reference group hypothesis is correct, there should be a positive relationship between wealth and fitness within each occupational group. However, given that clerks are generally poorer and of lower status than physicians, which implies that most physicians could have been clerks but not vice versa, the physicians nevertheless appear to have been behaving maladaptively by making social, economic, and reproductive decisions that led to them becoming physicians and not clerks. Thus, in other words, the foregoing example is about an evolved design which, given only the conditions outlined, leads in a particular modern environment to a maladaptive (i.e., off-track) outcome.

On the other hand, an adaptive (i.e., on-track) outcome might obtain if 1) temporary reproductive restraint allows one to maintain or increase social and economic success, and 2) social and economic and success continue over the long run, as they have in the past, to have a positive impact on inclusive fitness. ${ }^{16}$ Thus, in terms of the example, if competition to become a successful physician has been especially fierce during the 1970's and 80's, relative to competition among clerks, and if effort to reproduce reduces effort available for social and economic strivings (see Turke 1989), temporary reductions in reproduction by physicians may eventually allow increases in reproduction at some later time in life or even in subsequent generations

\footnotetext{
${ }^{16}$ In a partial review of the literature, Gaulin (1986) and Kaplan and Hill (1986) have concluded that even for males in the most developed societies there is no empirical foundation for the claim that wealth and inclusive fitness are inversely related. For females, evidence for an inverse relationship is strong enough to be termed suggestive only for brief periods of time, particularly the past 20-30 years. The point, they argue, is that such anomalies, if they exist, may turn out to be unnoticeable "blips" when viewed on an evolutionary time scale.
} 
(cf. Philippi and Seger 1989; Rogers 1989). In such a case, it may very well be adaptive to focus one's competitive efforts against other physicians, because it is other physicians, not clerks, who most threaten one's own social and economic standing, and because, in most cases, a physician's chance for social economic success depends on success as a physician. Thus, in other words, it may prove to be appropriate, even in today's technologically advanced societies, to make social, economic, and reproductive decisions in reference to how such decisions are being made by one's closest competitors. It is significant to note that, at least with regard to economic success, competing in such a manner produces results that are superior to those produced by competitive strategies based on absolute criteria (Frank 1985).

I have argued elsewhere (Turke 1989) that "demographic transition," the significant reduction in completed family size that occurs with modernization, may be best understood in terms of what here has been referred to as competition within reference groups. In a proximate sense, demographic transition is caused primarily by a decline in total fertility. The magnitude of this decline is illustrated in a study by Campbell and Wood (1987), which indicates that average total fertility is 6.2 in pretransition societies $(n=70)$ and 2.6 in posttransition societies $(n=70)$. Of course, mortality also declines during and after demographic transition, but, as evidenced by recent population growth rates, the mortality differential between pre- and posttransition societies usually has not been large enough to offset this differential since around the end of World War II. Therefore, on average, individuals in most pretransition societies are currently producing more surviving children than individuals in posttransition societies.

People in pretransition societies are generally poorer, by most economic measures, than people in posttransition societies, which implies that in such a comparison wealth and inclusive fitness are inversely related. However, I have demonstrated that kinship networks constitute an important source of wealth for child rearing, and that in this respect pretransition societies are wealthier than posttransition societies (Turke 1989). Thus, it may be that wealth and inclusive fitness are positively related after all. The next question raised, though, is why have people in some societies opted for modes of behavior that result in the breakdown of kinship networks and hence in the loss of a crucial reproductive resource? The answer, I have argued (Turke 1989), involves competition within reference groups, and may or may not produce an adaptive outcome.

A hypothesis accounting for a maladaptive (off-track) outcome has the following components. Throughout human evolutionary history individuals have been able to conceive more children than they can successfully rear. As a result, individuals have evolved both to limit births and to strive to acquirc as many resources as possible. However, some kinds of resources are acquired less by individual initiative than other kinds of resources. Specifically, it may be that one automatically has been a member of a functional extended kinship network more than one automatically has been an effective 
hunter, for example. Thus, individuals are expected to have evolved to be most preoccupied with the acquisition of resources that require individual initiative. For reasons that are as yet incompletely understood (see, e.g., Handwerker 1986; Turke 1989), it became increasingly efficient in some environments to acquire material resources in a manner that contributed to the breakdown of extended kinship networks. Thus, while many material resources became more abundant, other kinds of more personal resources, resources that once were provided by emotionally committed close kin, became increasingly scarce. Of course, although young children in all societies require material resources, even in technologically advanced societies they require a much greater abundance of personal services, including affection, training, and supervision.

The above changes, which may be flagged by the term "modernization," occurred first in some areas of Europe, but were soon exported to much of the rest of the world. In any event, because of the design produced by past selection pressures, one may hypothesize that individuals pursued, and continue to pursue modern modes of livelihood even though, as a result, personal resources that were once supplied in abundance by kin eventually became so diminished that fewer children can be reared than would be the case if less effort was devoted to economic success and more effort was devoted to preserving kinship networks (see Turke 1989 for details and discussion of additional ways in which diminished kinship networks led to a decrease in demand for children).

On the other hand, under some conditions the foregoing hypothesis can be modified to imply that Europeans (and later others) were, and are behaving adaptively by adopting resource aquisition strategies (ways of earning a living) that result in the breakdown of kinship networks and in fewer children. Specifically, escalating social competition, which for still obscure reasons began in Europe and was later exported, may have required the development and use of a number of strategies synonymous with modern living, such as monogamy, nationalism, and capitalism (all three of which are threatened by the existence of strong kinship networks) (see Alexander 1979; 1987; Betzig 1986; Turke 1989). In this milieu, it is possible that producing a relatively small number of children maximizes inclusive fitness. Were this true, it would be no more surprising than to find, for example, that birds living in a relatively inhospitable environment lay fewer eggs and fledge fewer offspring than conspecifics in a more hospitable environment.

All relatively slowly reproducing organisms are of course decended from organisms that reproduced more rapidly (at least if descent is traced far enough), and I believe it likely that in many instances this kind of progression (no normative implication intended) may have resulted from subgroups in the less hospitable areas of the species range evolving strategies that concentrate investment in fewer offspring. In turn, if parents who are in the habit of concentrating investment in fewer offspring maintain this habit when they come into contact with more hospitable environments, their offspring 
may often have a (socioeconomic and ultimately reproductive) competitive advantage over the offspring of parents who invest less in more offspring. In this manner an inflationary cycle of investing more in fewer offspring could be exported. Human demographic transition may represent a largely (or competely) faculative continuance of this progression. In contrast, the first demographic transition, the one associated with the advent of agriculture and an increase in fertility, may represent a change in the opposite direction.

\section{DISCUSSION}

Kitcher (1985) argues that evolutionary studies of human kinship have done little to advance our understanding other than to refute some very "odd remarks" by anthropologists claiming that genetic relationship has little to do with human kinship. He argues similarly for many other topics. One could, I think, make the case that evolutionary studies of kinship have done more than Kitcher suggests (see, e.g. Chagnon 1982; 1988; Hughes 1988). However, even the refutation of a few "odd remarks" is of great importance, given that prominent anthropologists can make such remarks only because their views of human nature are so much at odds with an evolutionarily informed view.

The same argument applies, I think, to a more recent remark, which is every bit as odd as the claim that genetic relationship has little to do with human kinship: "There is no more reason to expect high-status people to outreproduce low status people than there is to expect, say, heavy tobacco use to promote fitness" (Symons 1987b, p. 208). To the contrary, in the absence of well developed counter arguments, Darwinian theory provides about as much basis for expecting individuals of high status to outreproduce individuals of low status as it does for expecting individuals to favor close genetic kin (e.g., Daly and Wilson 1988), specific types of content to effect the Wason selection task in specific ways (Cosmides 1985), females to prefer males of high status (e.g., Symons 1979; Buss 1989), rapes to be committed primarily by disenfranchised males (Thornhill and Thornhill 1983), and etc. ${ }^{17}$

Hypotheses of the type criticized by Kitcher generally have sought, as a test, to determine whether current behavior is adaptive. Symons and others have taken-up Kitcher's line of argument at this juncture in arguing that

${ }^{17}$ Unlike for heavy tobacco use, we can reasonably expect wealth, status, and fitness to correlate because it is clear that at least some components of fitness have been, and still are, limited by access to resources, and because in human societies wealth and status have provided, and can still provide, access to the kinds of resources which promote fitness (e.g., food, mates, and safe haven). Similarly we can reasonably expect genetic relationship to affect human kinship systems and quality of interaction among kin-in ways which have been and are adaptive, because kin share genes, and because kin have interacted, and continue to interact, in ways which give opportunity for phenotypic altruism. Moreover, neither of the above expectations is refuted, or even much weakened, by the mere recognition of potential confounds (e.g., social welfare, on the one hand, and much increased interaction with nonkin, on the other). 
demonstrating that behavior is adaptive does not help to distinguish between alternative views of human nature. Here I have defended the point that hypotheses about adaptations are likely to be correct if they correctly predict an adaptive outcome, and therefore assessing current adaptiveness can contribute to an understanding of adaptations. A recent paper by Turke and Betzig (1985) provides an appropriate example, especially in that it has been characterized as being unconcerned with psychological mechanisms and therefore failing to contribute to our understanding of human nature (Symons 1989). In that paper, we analysed the relationship between wealth, status, and reproductive success (and some of its components) on Ifaluk, a traditional Micronesian atoll society. However, far from being unconcerned with psychological mechanisms, our main purpose was to present evidence that turned out to go against theoretical constructs of the human psyche that deem it likely that learning and culture will lead human behavior off-track with respect to adaptiveness.

[T]he proximate mechanisms that kept cultural behavior adaptive initially might have kept it adaptive subsequently (Flinn and Alexander 1982; Turke 1984) . . . This is not, however, the say that human behavior [today] must he adaptive. There are potentially valid theories predicting the decoupling of culture from natural selection: natural selection may usually operate too slowly to have checked the development of major nonadaptive trends (even though it apparently did not do so for thousands or millions of years while the capacity for culture was evolving); and cultural evoluation may have been significantly molded by selection of replicators other than genes, such as ideas or "memes" (Dawkins 1976; Durham 1976; 1982; Richerson and Boyd 1978; Cavalli-Sforza and Feldman 1981; and others). The crux here, however, is that neither of these modes of cultural evolution predicts that humans historically or currently strive to maximize genetic representation in future generations (Alexander 1979; Turke 1984) (Turke and Betzig 1985, pp. 85-86).

The present paper, however, goes beyond Turke and Betzig (1985), in so much as it discusses tests of increasingly detailed theoretical constructs of the human psyche. For example, determining that polyandrous marriage is carried out adaptively in a present-day contexts suggests that social and cultural problems, which are not uniquely related to Pleistocene hunting and gathering, and which continually introduce novelty, constituted primary selective pressures in the evolution of the human psyche; in turn, support is given to hypotheses which view the psyche as more general purpose (in the sense of being designed to deal with types of novelty) than has been implied by some evolutionary psychologists. This view of the psyche as relatively general purpose is consistent with similar conclusions being drawn about the mental apparatus of much simpler organisms (see West Eberhard 1987).

With regard specifically to the question of which humans bchave adaptively, the available evidence suggests that individuals living in traditional societies, that is, societies in which social organization is based primarily on kinship, behave adaptively (in the sense of the definition outlined at the 
beginning of the paper). The evidence is much more equivocal for more developed societies, although refinements in both theory and methods promise to yield firmer conclusions. For now, it is necessary to continue to consider a range of hypotheses about the nature of the human psyche. We cannot assume that human behavior is off-track, and in turn we cannot assume that the cause of our being off-track (if we are) is an evolved design for overcoming specific problems that are in some crucial respect unique to hunting and gathering in Pleistocene.

I thank Dick Alexander, Laura Betzig, Monique Borgerhoff Mulder, Lee Cronk, Kurt Hoop, Joe Manson, Randy Nesse, Bob Smuts, and Samantha Weber for constructive criticism, and Dick Alexander and Bob Smuts for allowing me to cite their unpublished manuscripts. As always, I'm grateful to Dick Alexander and Bill Irons for sharing their understanding of evolutionary theory. Preliminary versions of this paper were presented at the Michigan Evolution and Human Behavior Program's Spring Seminar (March 1989) and at the Human Behavior and Evolution Society's First Annual Meeting (Northwestern University, August 1989). Financial support has been provided by the Michigan Society of Fellows and the University of Michigan's Evolution and Human Behavior Program.

\section{REFERENCES}

Alcock, J. Ardent Adaptationism. Natural History 96: 4, 1987.

Alexander, R.D. The evolution of social behavior. Annual Review of Ecology and Systematics, 5: 325-83.

1979. Darwinism and Human Affairs. Seattle: University of Washington Press.

1987. The Biology of Moral Systems. Hawthorne, NY: Aldine.

1988. Evolution and human behavior: What does the future hold? In, L.L. Betzig, M.B. Mulder, and P.W. Turke, eds. Human Reproductive Behavior: A Darwinian Perspective.

1989. Evolution of the human psyche. In P. Mellars and C. Stringer, eds. The Human Revolution. University of Edinburgh Press.

1990. Epigenetic rules and Darwinian algorithms: The adaptive study of learning and development, in preparation.

Alexander, R.D. and K. Noonan. Concealment of ovulation, parental care, and human social evolution. Evolutionary Biology and Human Social Behavior. In N. Chagnon and W. Irons (Eds.). 1979, North Scituate, MA: Duxbury Press.

Barkow, J. The distance between genes and culture. Journal of Anthropological Research, 40: 368-379, 1984.

The elastic between genes and culture. Ethology and Sociobiology, 10: 111-129, 1989.

Becker, G. An economic analysis of fertility. In National Bureau of Economic Research. Demographic and Economic Changes in Developing Countries. 1960, Princeton: Princeton University Press.

Betzig, L.L. 1986. Despotism and Differentioal Reproduction: A Darwinian View of History. Hawthorne, NY: Aldine.

1988a. Adoption by rank on Inflauk. American Anthropologist 90: 111-119.

1988b. Mating and parenting in Darwinian perspective. In, L.L. Betzig, M.B. Mulder, and P.W. Turke, eds. Human Reproductive Behavior: A Darwinian Perspective. 1988b, pp. 3-20. Cambridge: Cambridge University Press.

- Rethinking human ethology: A response to some recent critiques. Ethology and Sociobiology, 10: 1989.

Betzig, L.L., M.B. Mulder, and P.W. Turke (Eds.). Human Reproductive Behavior: A Darwinian Perspective, 1988. Cambridge: Cambridge University Press. 
Borgerhoff Mulder, M. Cultural and reproductive success: Kipsigis evidence. American Anthroplogist, 89, 1987a.

- Resources and reproduction of women with an example from the Kipsigis. J. Zool. Lond. Ser. B, $1987 \mathrm{~b}$.

Boyd, R. and P. Richerson. Culture and the Evolutionary Process. 1985. Chicago: University of Chicago Press.

Buss, D. Sex differences in human mate preferences: evolutionary hypotheses tested in 37 cultures. Behavioral and Brain Sciences 12(1); 1-49, 1989.

Campbell, K.L. and J.W. Wood. Fertility in traditional societies. In Natural Human Fertility: Social and Biological Mechanisms. P. Diggory and S. Teper (Eds.), 1987. London: Macmillan.

Chagnon, N.A. Is reproductive success equal in egalitarian societies? In, N.A. Chagnon and W. Irons (Eds.). Evolutionary Biology and Human Social Behavior: An Anthropological Perspective, 1979. North Scituate, MA: Duxbury Press.

- Man the rule breaker. In King's College Sociobiology Group, eds., Current Problems in Sociobiology, 1982. Cambridge University Press.

1988a. Life histories, blood revenge, and warfare in a tribal society. Science 129: 985992.

- - Male Yanomamo manipulations of kinship classifications of female kin for reproductive advantage. In L. Betzig, M. Borgerhoff Mulder and P. Turke (Eds.). Human Reproductive Behavior, 1988b. London: Cambridge University Press.

Cloak, F.T. Is a cultural ethology possible? Human Ecology, 3: 161-182, 1975.

Clutton-Brock, T.H. Reproductive Success. Chicago: University of Chicago Press, 1988.

Cosmides, L. Deduction or Darwinian algorithms? An explanation of the elusive content effect on the Wason selection task. Ph.D. Dissertation, Harvard University, University Microfilms, 1985.

Cosmides, L. and Tooby, J. From evolution to behavior: Evolutionary psychology as the missing link. In, J. Dupre (Ed.). The Latest on the Best: Essays on Evolution and Optimality, 1987. Cambridge, MA: MIT Press.

A Computational Theory of Social Exchange. Ethology and Sociobiology, 10: 51-97, 1989.

Crook, J. and S. Crook. Tibetan polyandry: problems of adaptation and fitness. In Human Reproductive Behaviour: A Darwinian Perspective, L. Betzig, M. Mulder, and P. Turke (Eds.). 1988. Cambridge: Cambridge University Press.

Daly, M. and M. Wilson. 1986. A theoretical challenge to a caricature of Darwinism. (comment on Vining, 1986).

Homicide. Hawthorne, NY: Aldine De Gruyter, 1988.

Dawkins, R. 1976. The Selfish Gene. NY: Oxford University Press.

- 1982. The Extended Phenotype. San Francisco: Freeman.

- The Blind Watchmaker, 1986. NY: Norton.

Dickemann, $M$. Female infanticide and the reproductive strategies of stratified human societies: A preliminary model. In, Evolutionary Biology and Human Social Behavior: An Anthropological Perspective. N.A. Chagnon and W. Irons (Eds.). 1979. North Scituate, MA: Duxbury Press.

Dunbar, R.I.M. Adaptation, fitness and the evolutionary tautology. In, Current Problems in Sociobiology, King's College Sociobiology Group (Eds.). 1982. Cambridge: Cambridge University Press.

Durkheim, E. The Rules of Sociological Method. Glencoe: Free Press, 1958.

Easterlin, R.A. The economics and sociology of fertility: A synthesis. In, Historical Studies of Changing Fertility, C. Tilly (Ed.). 1978. Princeton: Princeton University Press.

- Birth and Fortune. New York: Basic Book, 1980.

Essock-Vitale, S. The reproductive success of wealthy Americans. Ethology and Sociobiology, 5: 45-9, 1984.

Flinn, M.V. Uterine versus agnatic kinship variability and associated cousin marriage preferences: An evolutionary biological analysis. In, Natural Selection and Social Behaviour: Recent Research and New Theory, R.D. Alexander and D.W. Tinkle (Eds.). 1981. New York: Chiron.

- Resources, reproduction, and mate competition in human societies. Behavioral and Brain Sciences, 10: 305-307, 1987. 
Flinn, M. and R. Alexander. Culture theory: the developing synthesis from biology. Human Ecology 10: 383-400, 1982.

Frank, R. Choosing the Right Pond. 1985. Princeton, NJ: Princeton Univ. Press

Freedman, D. The relation of economic status to fertility. American Economic Review. 53 . 414-426, 1963.

Freedman, D. and A. Thornton. Income and fertility: The elusive relationship. Demography, 19: 65-79, 1982.

Gaulin, S.J.C. Comment on "Sociai versus reproductive success: The central problem of human sociobiology' by D.R. Vining. The Behavioral and Brain Sciences, 9: 219, 1986.

Gaulin, S. and A. Schlagel. Paternal confidence and parental investment: A cross cultural test of a sociobiological hypothesis. Ethology and Sociobiology, 1: 301-309, 1980.

Gibbs, H. Cultural evolution of male song types in Darwin's medium ground finches, Geospiza fortis. Animal Behaviour 39: 253-263, 1990.

Gould, S.J. Ever Since Darwin, essay 9, 1977. NY: W.W. Norton.

Gould, S.J. and R.C. Lewontin. The spandrels of San Marco and the Panglossian paradigm: A critique of the adaptationist programme. Proceedings of the Royal Society of London, 205: 581-598, 1979.

Grafen, A. On the uses of data on liftetime reproductive success. In Reproductive Success, pp. 454-471, T. Clutton-Brock (Ed.). 1988. Chicago: University of Chicago Press.

Hamilton, W.D. The genetical evolution of social behaviour, I, II. Journal of Theoretical Biology, 7:1-52, 1964.

—. The moulding of senescence by natural selection. Journal of Theoretical Biology, 12: 12$45,1966$.

Hamilton, W.D. and M. Zuk. Heritable true fitness and bright birds: a role for parasites? Science, 218: 384-387, 1982.

Handwerker, P. The modern demographic transition: an analysis of subsistence choices and reproductive consequences. American Anthropologist, 88: 400-417, 1986.

Hill, E. and Hill. Status Enhancement and Fertility. Paper presented at the Human Behavior and Evolution Society Meeting, August 1989, Northwestern University.

Hoffmann, A. and A. Cacoyianni. Selection for territoriality in Drosophila melanogaster: correlated responses in mating success and other fitness components. Animal Behaviour 38: 23-34, 1989.

Holmes, W. and P. Sherman. The ontogeny of kin recognition in two species of ground squirrels. American Zoologist, 22: 491-517, 1982.

Hughes, A. Kin networks and political leadership in a stateless society, the Toda of South India. Ethology and Sociobiology, 9: 29-44, 1988.

Humphrey, N.K. The social function of intellect. In, Growing Points in Ethology. P.P.G. Bateson and R.A. Hinde (Eds.). 1976. Cambridge: Cambridge University Press.

Irons, W. Natural selection, adaptation, and human social behavior. In Evolutionary Biology and Human Social Behavior: An Anthropological Perspective N. Chagnon and W. Irons, (Eds.). pp. 4-39, 1979a. North Scituate, MA: Duxbury Press.

- Cultural and biological success. In Evolutionary Biology and Human Social Behavior: An Anthropological Perspective, N.A. Chagnon and W. Irons (Eds.). 1979b. North Scituate, MA: Duxbury Press.

Is Yomut social behavior adaptive? Sociobiology: Beyond Nature/Nuture? G. Barlow and J. Silverberg (Eds.). 1980. Boulder, CO: Westview Press.

- - Human female reproductive strategies. Social Behavior of Female Vertebrates, S.K. Wasser (Ed.). 1983. New York: Academic Press.

Johnson, N.E. and S. Lean. Relative income, race, and fertility. Population Studies, 39: 99$112,1985$.

Kaplan, H. and K. Hill. Sexual strategies and social-class differences in fitness in modern industrial societies. The Behavioral and Brain Sciences, 9:167-216. (comment on Vining 1986), 1986.

Kitcher, P. Vaulting Ambition, 1985. Cambridge, MA: MIT Press.

Kluger, M. The history of bloodletting. Natural History, 87: 78-83, 1978.

Kummer, H. Primate Societies, 1971. Arlington Heights, IL: AHM Publishing Corp.

Kurland, J. Proletarian hominids on the rampage, 1986. (Comment on Vining 1986). 
Lee, R. and I. Devore. Man the Hunter, 1968. Chicago: Aldine.

Maynard Smith, J. The Evolution of Sex, 1978. Cambridge University Press.

__ Did Darwin Get it Right? 1988. Great Britain: Chapman and Hall.

Mayr, E. How to carry out the adaptationist program? The American Naturalist, 12: 324-334, 1983.

Mueller, E. and K. Short. Effects of income and wealth on the demand for children. In, Determinants of Fertility in Developing Countries, R.A. Bulato and R.D. Lee (Eds.). 1983. New York: Academic Press.

Murdock, G.D. and D.R. White. Standard cross-cultural sample. Ethnology, 8: 329-369, 1969.

Partridge, L. Mate choice increases a component of offspring fitness in fruit flies. Nature, 283 : 290-291, 1980.

Philippi, T. and J. Seger. Hedging one's evolutionary bets, revisited. Trends in Ecology and Evolution 4: 41-44, 1989.

Rogers, A. Evolutionary economics of reproduction. Paper presented at Human Behavior and Evolution Society First Annual Meeting, August 1989, Northwestern University.

Ruse, M. Teleology in biology: is it a cause for concern? Trends in Ecology and Evolution 4: 51-54, 1989.

Sahlins, M. The Use and Abuse of Biology, 1976. Ann Arbor: University of Michigan Press.

Sherman, P. The levels of analysis. Animal Behaviour 36: 616-619, 1988.

Silk, J. Adoption in Oceania. American Anthropologist, 82: 799-820, 1980.

- Human adoption in evolutionary perspective. Human Nature, 1: 25-52, 1990.

Smuts, R.W. From evolution to behavior: evolutionary psychology as the missing link, Unpublished manuscript.

Stadden, J. Optimality Theory and Behavior. In The Latest on the Best, J. Dupré. (Ed.). 1987. Cambridge, MA: MIT Press.

Symons, D. The Evolution of Human Sexuality. New York: Oxford, 1979.

- - . If we're all Darwinians, what's all the fuss about? In Darwinism and Psychology. C. Crawford, D. Krebs, and M. Smith (Eds.). 1987a. Hilldale, NJ: Lawrence Erlbaum.

-. Reproductive success and adaptation. Behavioral and Brain Sciences, 10: 788-789, $1987 \mathrm{~b}$.

A Critique of Darwinian Anthropology. Ethology and Sociobiology, 10: 131-144, 1989.

Thornhill, R. The study of adaptation. In Interpretation and Explanation in the Study of Animal Behavior, Vol. II. Bekoff and D. Jamieson (Eds.). 1990. Westview Press: Boulder, CO.

Thornhill, R. and N. Thornhill. Human Rape: an evolutionary analysis. Ethology and Sociobiology 4: 137-173, 1983.

Tinbergen, N. On aims and methods of ethology. Zeitscrift fürTierpsychologie, 20: 410-433, 1963.

Tooby, J. and L. Cosmides. Evolutionary Psychology and the Generation of Culture, Part I: Theoretical Considerations. Ethology and Sociobiology, 10: 29-40, 1989.

Trivers. R.L. The evolution of Social Behavior. 1985. Menlo Park: Cummings.

Turke, P.W. On what's not wrong with a Darwinian theory of culture. American Anthropologist, 86: 663-668, 1984.

- Fertility Determinants on Ifaluk and Yap: Tests of Economic and Darwinian Hypotheses. Ph.D. Dissertation, 1985. Northwestern University, University Microfilms, Ann Arbor, MI.

- Helpers at the nest: childcare networks on Ifaluk. In Human Reproductive Behavior, Betzig, L., M. Borgerhoff Mulder, and P. Turke (Eds.). 1988. London: Cambridge University Press.

- Evolution and the demand for children. Population and Development Review, 15: 61$90,1989$.

Turke, P.W. and L.L. Betzig. Those who can do: Wealth, status, and reproductive success of Ifaluk. Ethology and Sociobiology, 6: 79-87, 1985.

Vining, D. Social versus reproductive success: The central problem of human sociobiology. The Behavioral and Brain Sciences, 9: 167-216, 1986.

Wade, M. Measuring sexual selection. In, Sexual Selection: testing the alternatives, J.W. Bradbury and M. Anderson (Eds.). 1987. pp. 197-2, 7. NY: Hohn Wiley and Sons.

Weinherg, E. Iron withholding: A defense against infection and neoplasia. Physiological Reviews, 64: 65-102, 1984. 
West-Eberhard, M.J. Flexible strategy and social evolution. In, Animal Societies: Theories and Facts. Ito, Y., J. Brown, and J. Kikkowa (Eds.). 1987. Tokyo: Japan Sci. Soc. Press. Williams, G.C. Pleiotropy, natural selection, and the evolution of senescence. Evolution, 11: 32-39, 1957

—. Adaptation and Natural Selection: A Critique of Some Current Evolutionary Thought, 1966. Princeton: Princeton University Press.

- - In defense of reductionism in evolutionary biology. Oxford Surveys In Biology, 2: 1-27, 1985. 